\title{
Chemical Synthesis and Characterization of Conducting Polyaniline
}

\author{
Salah Abdulla Hasoon*
}

Sally Adel Abdul-Hadi

Received 25/4/2019, Accepted 1/10/2019, Published 1/3/2020

(9)

\begin{abstract}
:
The polyaniline powder was chemically manufactured by direct oxidation of aniline. The resulting polymer was characterized by the results of optical, measurements by (FT-IR) spectroscopy, we have detected some of the absorption peaks located at $3498,2858 \mathrm{~cm}^{-1}$, which correspond N-H vibrations, and C$\mathrm{H}$ expansion of the aromatic ring respectively as well as stretching vibrations of quinoid ring have been observed. Structural properties, such as the surface topography using an atomic force microscope (AFM), and Surface composition by (SEM) have been studied. The structure of some pellets of polyaniline powder have been examined by using analytical X-ray diffraction technique, the pattern of observed lines shows a crystalline nature and three large peaks observed.
\end{abstract}

Key words: Atomic force microscopy, Chemical synthesis, Conductive polyaniline, Scanning electron microscopy.

\section{Introduction:}

Polyaniline is an organic semiconductor polymer that has been discovered since more than 150 years. However, since the early 1980s, polyaniline has taken a strong interest from researchers due to the discovery of its electrical conductivity $(1,2,3)$. It has adopted a basic place among the locations of the conductive polymers. Polyaniline is an unusual phenyl, its polymer structure is characterized by chemical elasticity, and the NH-series in the polymer chain is bounded by a phenyl ring from both sides(4). It refers to a group of molecules that are conductive to the electrical conductivity and able to change from insulator to conductor through oxidation processes (5). Polyaniline can be produced by the process of aniline polymerization with many types of organic oxides and specific percentages of proton acids and under certain conditions of reaction (6). In fact, the total heteroatoms are stable while exposed to oxygen not as in polyacetylene. Therefore, the physical and chemical properties of these compounds make them particularly striking, and have a large electrical conductivity about $10^{-5} \mathrm{~S} / \mathrm{cm}(7,8)$. Also it has the scope of work in the field of Photovoltaic organic cells $(9,10)$, Gas sensors $(11,12)$, Solid electrical capacities (13), Electric windows and screens, and Batteries polymeric (14).

Department of Physics, College of Science for Women, University of Baghdad, Baghdad, Iraq.

*Corresponding author: salahabd55@yahoo.com

*ORCID ID: 0000-0003-1829-218X
Polyaniline has environmental stability as well as being easy to be vaccinated using protein acids $(15,16)$. We have synthesized and characterized polyaniline powder was obtained form in chemical via being used as conducting gas sensor for Acidbase reaction material

\section{Materials and Method:}

The chemical polymerization of emerald hydrochloride salt has been synthesized easily as a partially crystallized black-green precipitate, by oxidative polymerization of $0.2 \mathrm{M}$ aniline with 0.25 $\mathrm{M}$ of the oxidizing agent ammonium peroxydisulfate $\left[\left(\mathrm{NH}_{4}\right)_{2} \mathrm{~S}_{2} \mathrm{O}_{8}\right]$ in an aqueous acid medium, this oxidative polymerization needs two electrons per one aniline molecule. Aniline was purchased from Sigma-Aldrich $(465.6 \mathrm{mg}$ ), it was dissolved in distilled water in a volumetric flask1 of $(25 \mathrm{ml})$. The flask 1 is then cooled with ice. Ammonium peroxydisulfate $(1.426 \mathrm{~g})$ was dissolved in water also of $(25 \mathrm{ml})$ in flask 2 , then a Hydrochloric acid was used with $1 \mathrm{M} / 1(1.823 \mathrm{~g})$ was dissolved in water and placed in $(50 \mathrm{ml})$ volumetric flask then we divided this acidic solution into two portions of $(25 \mathrm{ml})$, One of this portion was added to flask1 and the other one was also added to flask2. Then, we saved each baker separately for an hour at a room temperature degree. Thereafter, we mixed the two solutions slowly with magnetic stirring for a full day, as shown in Fig 1. By oxidizing the solution with added dropwise to 
the addition funnel while maintaining the constant temperature by addition of ice, when all the contents of the bulb are poured then, the mixture is colored after 3 to 5 minutes of colorless to a colloid solution of dark green precipitate. This is then washed with distilled water and then the hydrochloric acid solution, thence filtered under a vacuum and dried in an oven at $\left(40 \mathrm{C}^{\circ}\right)$ for 48 hours. The procedures of polymerization are shown in Fig. 1. The synthesis powder doped polyaniline was dissolved with water only in the absence of hydrochloric acid to have undoped polyaniline.

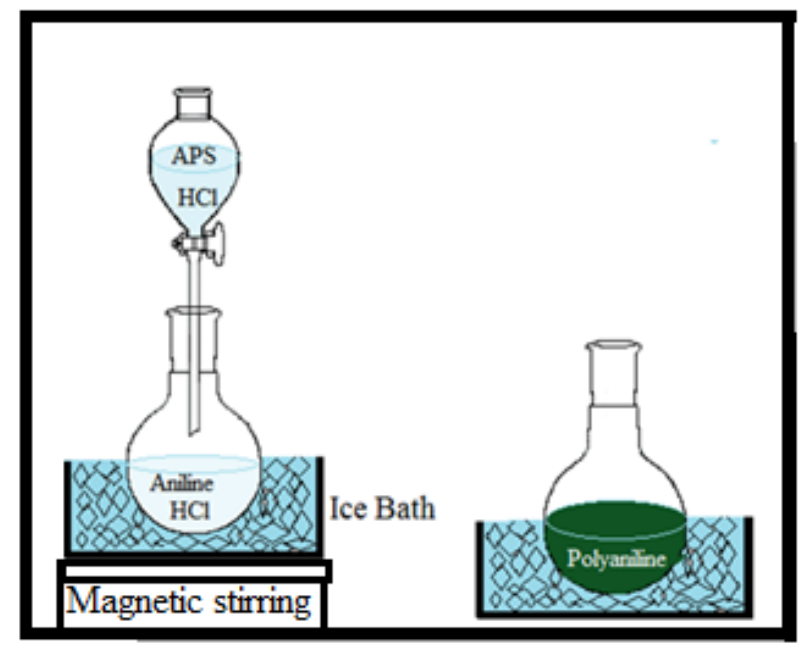

Figure 1. Chemical syntheses of polyaniline.

\section{Preparation of Gas Sensors}

Polyaniline can be used to manufacture a detector by connecting it to an electric circuit to measure its resistance by exposing it to vapor of a base such as ammonium hydroxide, recording its resistance and then exposed to acid vapor for the second time to measure its resistance again. For studying the reversible cyclic doping- dedoping, that corresponds charge - discharge states, the samples of polyaniline have been exposed to room temperature to the vapors of ammonia hydroxide and hydrochloric acid respectively. In other words the conductivity of polyaniline is a function of the rate of protons (17). Once polymerization is over, the precipitate solution of polyaniline, has been nominated by filtration, dried under vacuum, and washed over and over with $\mathrm{HCl}$, taking a small piece of homogeneous adhering polymer and linked to the ends of avometer to measure its resistance, where primary resistance is measured at room temperature and then exposed to the vapor of $\mathrm{NH}_{3}$, which pulls the protons of polyaniline and then become natural form or dedoping state. An increase in resistance readings over time (decrease in conductivity) and then exposed to the vapor of HCL acid vapor, where resistance readings decrease over time

\section{Result and Discussion: Infrared Spectroscopy (FT-IR)}

FT-IR ensembles of polyaniline model primed by $(0.2 \mathrm{M})$ of aniline via chemical polymerization are shown in Fig. 2. The assignments of the essential absorption bands are at $\left(3498 \mathrm{~cm}^{-1}\right)$ are produced by $\mathrm{N}-\mathrm{H}$ vibrations (18). The absorption bands at $\left(2858 \mathrm{~cm}^{-1}\right)$ are consequent of the unbalanced $\mathrm{C}-\mathrm{H}$ expansion of the aromatic ring (15). The pic at $\left(2375 \mathrm{~cm}^{-1}\right)$ is related to stretching vibration of $(\mathrm{O}-\mathrm{H})$ group (19). The crests at (1519, 1469,1458 , and $1423 \mathrm{~cm}^{-1}$ ) produced from $\mathrm{C}=\mathrm{C}$ stretching of quinoid ring and vibration of benzennoid ring $(20,21,22)$. Bands appeared at $\left(1300,1375 \mathrm{~cm}^{-1}\right)$ are attributed to $\mathrm{C}-\mathrm{N}$ stretching vibration in the alternate units of quinoidbenzenoid-quinoid rings and $\mathrm{C}=\mathrm{N}^{+}$stretching to the quinoid structure respectively (22). The vibration band at $\left(1238 \mathrm{~cm}^{-1}\right)$ can be assigned to $\mathrm{C}-\mathrm{N}$ stretching vibration mode in benzenoid ring (23, 24). While the vibrations at $(1141,1111,1076$ and $1037 \mathrm{~cm}^{-1}$ ) are characteristic to $\mathrm{C}-\mathrm{H}$ bending vibration (25). Finally, the absorption peaks at $\left(628,675,736,759\right.$ and $\left.871 \mathrm{~cm}^{-1}\right)$ formed $\mathrm{C}-\mathrm{H}$ bending vibration out-of plane $(20,21,25)$.

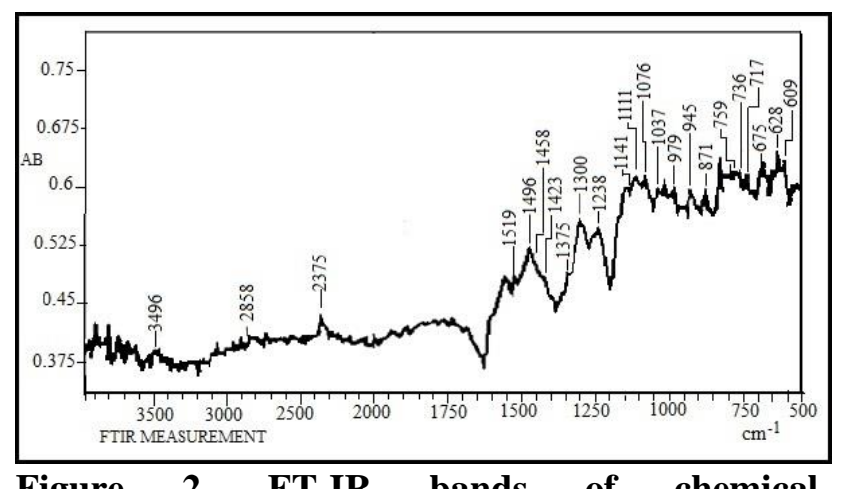

Figure 2. FT-IR bands of chemical polymerization of polyaniline.

\section{Atomic force microscopy (AFM)}

Figure. 3 shows the images of the atomic force microscope of a chemically prepared sample of PNAI powder. AFM technique gives us information about surface features of sample. Images have been taken to the survey area $(10110 \mathrm{~nm} \times 10151 \mathrm{~nm})$. Fig. 3 (a) shows a two-dimensional imaging of the sample surface. The surface roughness rate $(0.714$ $\mathrm{nm})$ and the mean square root $(0.846)$ were found. Fig. 3 (b) shows a three-dimensional image of the sample surface, which shows granular interference, formed by grooves and part of which appears in large conglomerates and worm-like. Fig. 3 (c) shows a graph of the distribution of granular aggregates. Granules are equal to (135.54 nm). This indicates that the particles of the material are very 
large nanoparticles, and the rest of the sizes were found. The percentages of the remaining volumes were found to be $10 \%$ of the granule size $(100 \mathrm{~nm})$ $(26,27,28), 50 \%$ for $(130 \mathrm{~nm})$ and $90 \%$ for $(170$ $\mathrm{nm})$.
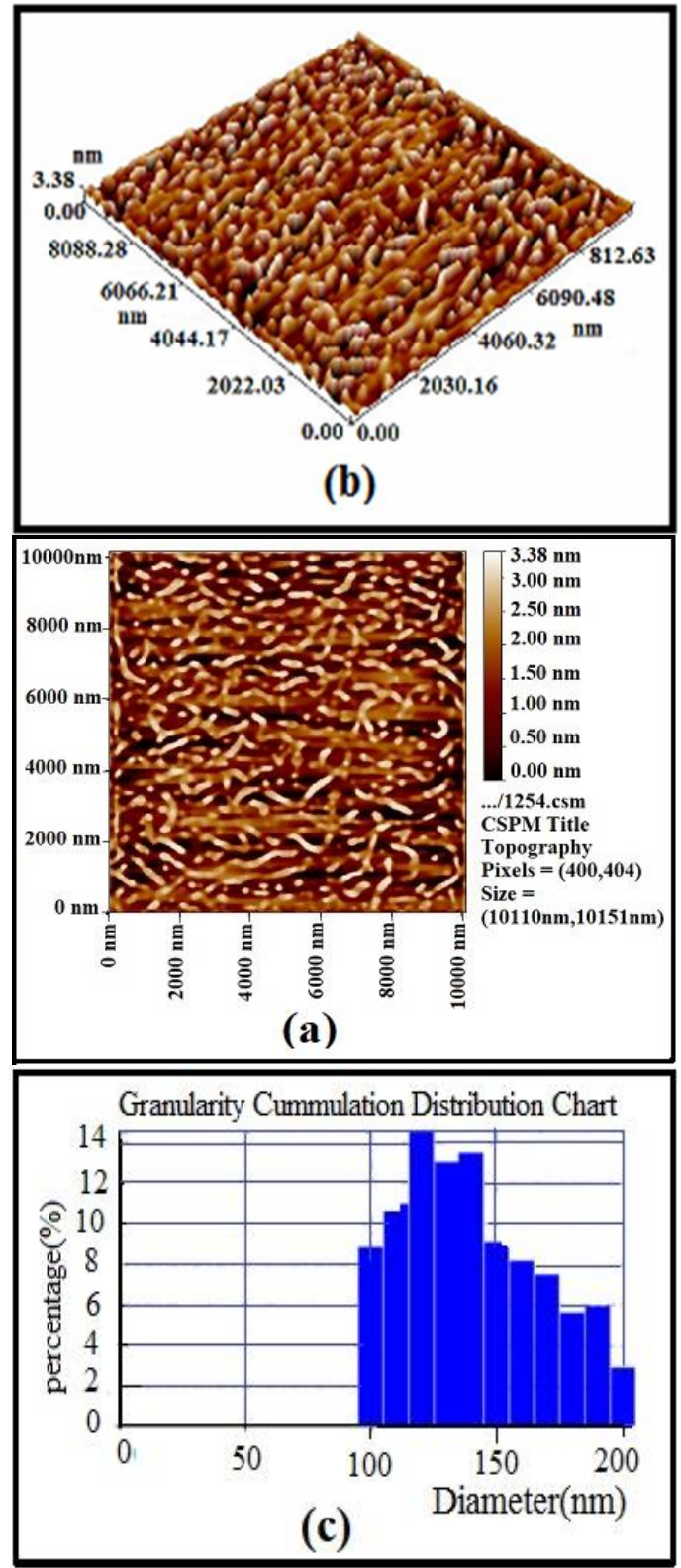

Figure 3. Atomic force microscopy images of the sample powder appears PNAI chemically (a) image analytical 2D, (b) Image 3D, (c) A chart of the distribution rate of particle size.

\section{Scanning Electron Microscopy (SEM)}

The SEM images of the PANI powder are shown ready chemically, with clusters and gathering of powder grains forming large spherical aggregates as shown in Fig. 4 (a), while Fig. 4 (b) shows a closeup image of one granule showing its formation in layers and layers of monoliths, some of which are made up of a spherical shape and the particle size of about $(1 \mu \mathrm{m})$ as mentioned in the literature (29).

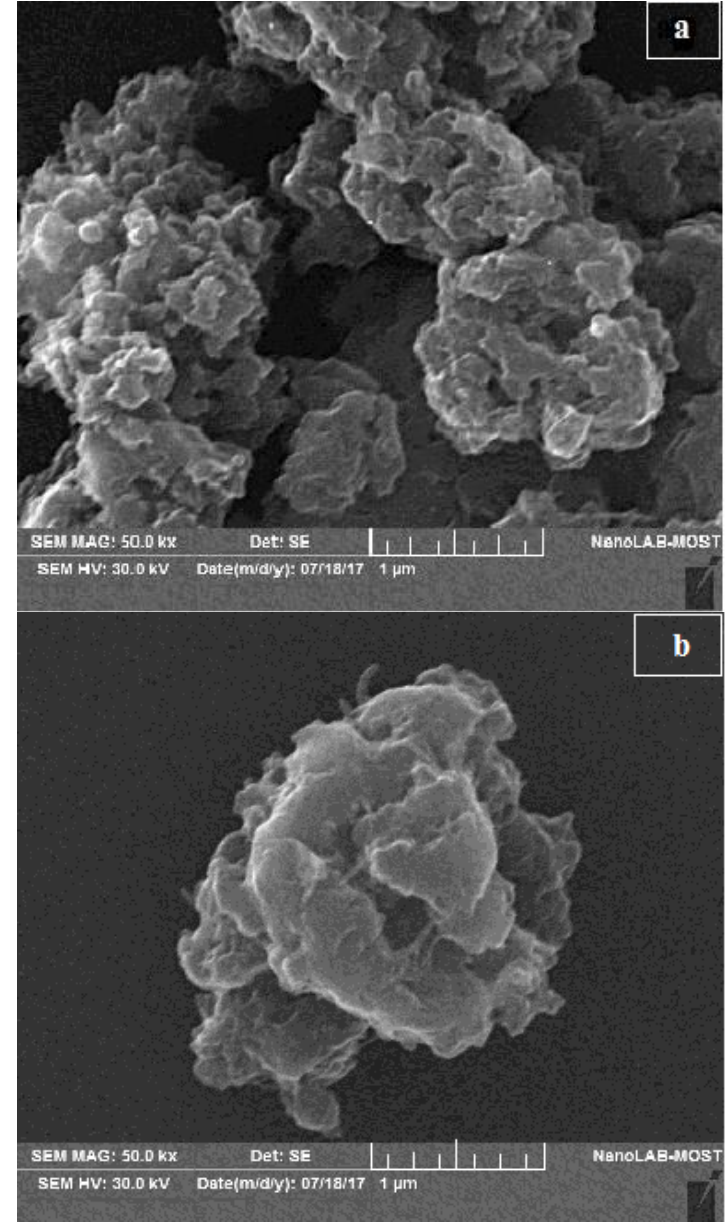

Figure 4. Shows SEM images of chemically prepared PANI powder, (a) image of PANI powder form, (b) rounded image of one granule.

\section{X-ray diffraction analysis}

Figure. 5 shows the $\mathrm{x}$-ray reflection of the powder of polyaniline. It appears that the PANI is crystalline nature and shows three large peaks. This characteristic peak of PANI is attributed to the periodicity in perpendicular and parallel directions of the polymer chain. The peaks were observed at $2 \theta$ angle for reflection levels at $15^{\circ}, 20.5^{\circ}$ and $25.2^{\circ}$, corresponding to the following reflection levels (101), (020), (200) respectively, similar to those observed by others $(30,31)$. At the same time, the main peak shows a significant increase in intensity and can be attributed to an increase in the size of the crystals of the powder, and the crystalline volume was created using the Scherer's relationship of the polyaniline powder about 30.58 $\mathrm{nm}$, which is comparable to previous research(2). 


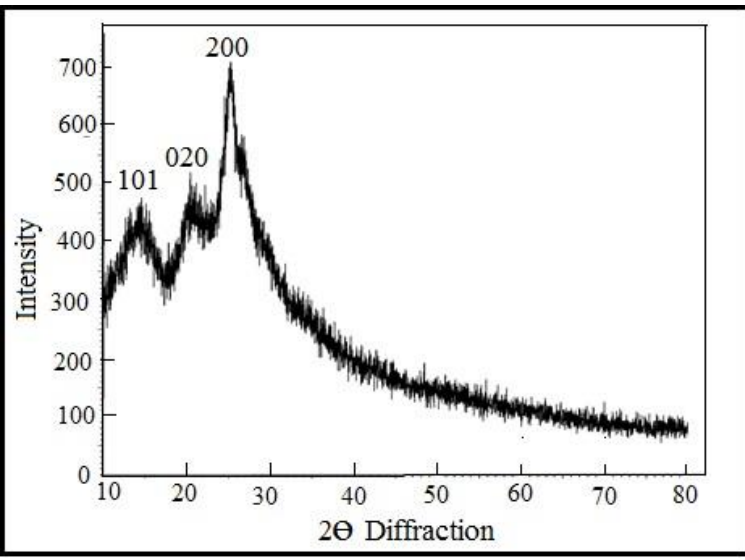

Figure 5. X-ray diffraction of polyaniline powder prepared by a chemical method.

\section{Sensor Measurements}

Fig.6 shows the characteristics measurements of the activated polyaniline, the exposure of polyaniline to ammonia gas vapors, which increases the resistance with time after exposing to ammonia gas vapors because ammonia withdraws the protons from polyaniline and thus removes the doping and the loss of conductivity, and when environment is displaced by air, the resistance almost gets back to its initial value. A similar behavior is presented in Fig.7 of the exposure of polyaniline to HCL, which increases the rate of doping with increasing exposure time. $(32,33,34)$

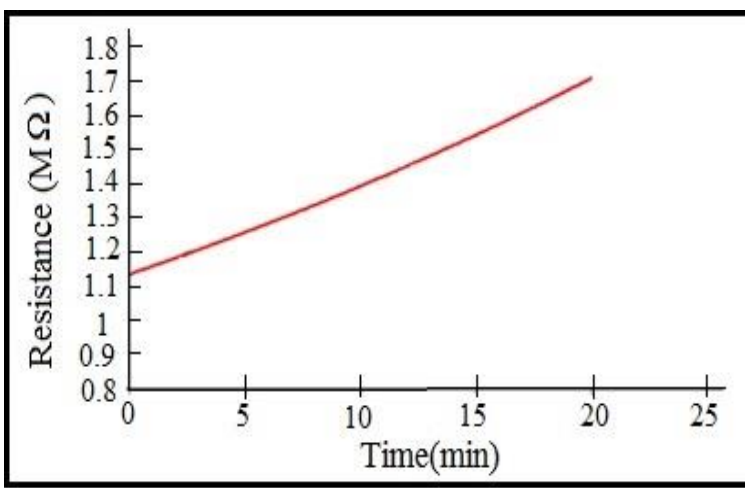

Figure 6. Shows the exposure of polyaniline to ammonia gas.

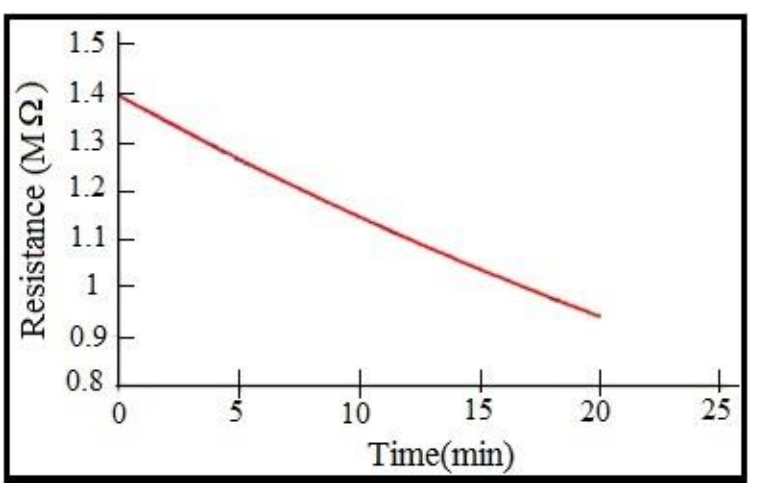

Figure 7. Shows the exposure of polyaniline to HCL.

\section{Conclusion:}

The polyaniline powder is prepared by the chemical method using acidic medium with ammonium persulfate, the AFM results show a particle size of about $135.54 \mathrm{~nm}$, while the study shows SEM particle form agglomerated and dendritic. The study of the infrared spectrum of the polyaniline powder shows an increase in the intensity of the spectrum whenever the frequency is less. The X-ray diffraction measurement shows a particle size of about $30.58 \mathrm{~nm}$.

\section{Acknowledgements}

The authors thank the Department of Physics, College of Science for Women, University of Baghdad for given that the required research capabilities.

\section{Conflicts of Interest: None.}

\section{References:}

1. Vivekanandan J, Ponnusamy V, Mahudeswaran A, Vijayanand PS. Synthesis, characterization and conductivity study of polyaniline prepared by chemical oxidative and electrochemical methods. Appl Sci Res. 2011; 3(6):147-153.

2. Fernando J, Vedhi C. Synthesis, Spectral and Electrochemical Characterization of Adipic Acid Doped Polyaniline. Int J Sci Technol. 2015; 3(4): 166-173.

3. Buvaneswari KM, Janarthanan M. Polyaniline Nanofibers and Their Application. Int J Curr Res Dev. 2014; 4(2) :29-37.

4. Ninh DH, Thao TT, Long PD, Dinh NN. Characterization of Electrochromic Properties of Polyaniline Thin Films Electropolymerized in $\mathrm{H}_{2} \mathrm{SO}_{4}$ Solution. J Org Polym Mater. 2016 Jan 7;6(01):3037.

5. Bavane RG. Synthesis and Characterization of Thin Films of Conducting Polymers for Gas Sensing Applications. SOPS NMU: Jalgaon; 2014. Chapter 3, Synthesis of Polyaniline (PANI); p. 22-37.

6. Keivani MB, Zare $\mathrm{K}$, Aghaie $\mathrm{M}$, Aghaie $\mathrm{H}$, Monajjemi M. Synthesis of Nano Conducting Polymer Based Polyaniline and it's Composite: Mechanical Properties, Conductivity and Thermal Studies. E-J Chem Chem. 2010; 7(1): 105-110.

7. Gvozdenović M, Jugović B, Stevanović J, Trišović $T$, Grgur B. Electrochemical polymerization of aniline.. 2011; Ewa Schab-Balcerzak (Ed.), ISBN: 978-953307-693-5 InTech.

8. Gvozdenović M, Jugović B, Jambrec D, Stevanović J, Grgur B. Application of polyaniline in corrosion protection of metals. Sci Pap. 2012; 53(4):353-360.

9. Glenis S, Frank AJ. Schottky barrier formation between poly (3-methylthiophene) and n-type cadmium sulfide. Synth Met.1989; 28(1): 681-686.

10. Vidal JC, García E, Castillo JR. In situ preparation of a cholesterol biosensor: entrapment of cholesterol 
oxidase in an overoxidized polypyrrole film electrodeposited in a flow system: determination of total cholesterol in serum. Anal Chim Acta.1999; 385(1):213-222.

11. Grgur BN, Gvozdenović MM, Stevanović J, Jugović BZ, Marinović VM. Polypyrrole as possible electrode materials for the aqueous-based rechargeable zinc batteries. Electrochimica Acta. 2008; 53(14):46274632.

12. Jones WD. Isotope effects in $\mathrm{C}-\mathrm{H}$ bond activation reactions by transition metals. Acc Chem Res. 2003; 36(2): 140-146.

13. Chougule MA, Pawar SG, Godse PR, Mulik RN, Sen S, Patil VB. Synthesis and Characterization of Polypyrrole (PPy) Thin Films. Soft Nanosci Lett. 2011;1(1):6-10.

14. Wallace GG, Spinks GM, Teasdale P. Conductive electroactive polymers, Technomic Pub. Co. Inc., USA. 1997; 107-125.

15. Rami S. Synthesis, Characterization, and Electrochemical Properties of Polyaniline Thin Films. University of South Florida. Graduat M Sc theses and dissertations, University of South Florida; 2015; :168.

16. Ramalingam RJ, Al-Lohedan HA, Radhika T. Synthesis,surface and textural characterization of $\mathrm{Ag}$ doped poluaniline-SiO2 (pang-Ag/rha) nanocomposites derived from biomass materials. Dig. J Nanomater Bios.2016;11(3): 731-740 .

17. Hassan TA, Al-Essa IM, Al-Ajaj EA, Ali AKM. Fabrication of Polyaniline-Carbonnanofibers for Hydrochloric Acid and Ammonia Sensing at Room Temperature. Eng \& Tech J. 2014; 32B(4):710-719.

18. Kondawar SB, Acharya SA, Dhakate SR. Microwave assisted hydrothermally synthesized nanostructure zinc oxide reinforced polyaniline nanocomposites. Adv Mat Lett. 2011; 2(5): 362-367.

19. Bhadra J, Al-Thani NJ, Karmakar S, Madi NK. Photo-reduced route of polyaniline nanofiber synthesis with embedded silver nanoparticles. Arab J Chem.2019; 12(8), 4848-4860.

20. Ratheesh R, Viswanathan K. Chemical Polymerization of Aniline Using Para-toluene Sulphonic Acid. IOSR J Appl Phys. 2014; 6(1): 1-9.

21. Hasoon SA. Electrochemical polymerization and Optical Vibrations of Polyaniline Films, Int J Inn. ovat. Res Sci Eng Technol. 2014;3:9763-9772.

22. Ibrahim K A. Synthesis and characterization of polyaniline and poly(aniline-co-o-nitroaniline) using vibrational spectroscopy, Arab J Chem. 2017; 10:
52668-52674.

23. Vijayakumar B, Anjana KO, Rao G, Ranga. Polyaniline/clay nanocomposites: preparation, characterization and electrochemical properties. In: IOP Conference Series: Mater Sci Eng. IOP Publishing; 2015;73:012112.

24. Hasoon SA, Abdul-hadi SA. Optical, Structural and Electrical Properties of Electrochemical Synthesis of Thin Film of Polyaniline. Baghdad Sci. J. 2018; 15(1):73-80.

25. Hidayat AT, Kusumaatmaja A, Chotimah, Soekrisno R, Triyana K. Effect of polyaniline polymerization methods on the preparation of electrospun polyaniline nanofiber. In: AIP Conference Proceedings. AIP Publishing; 2016;1755:150015.

26. Sewench N Rafic, Selma M H Al-Jawad, Mustafa M Muhsen, Synthesized and Study the Structural and Morphological Properties of Polyaniline-Cadmium Sulfide Nanocomposite. ANJS, 2017; 20 (3):91-98

27. Hasoon S A, Abdul-Hadi S A, Optical, Structural and Electrical Properties of Electrochemical Synthesis of Thin Film of Polyaniline. BSJ, 2018,15(1):73-80

28. Deshpande N G, Gudage Y G , Sharma R, Vyas J C, Kim J B, Lee Y P. Studies on tin oxide-intercalated polyaniline nanocomposite for ammonia gas Sensing applications, Sensor Actuat B-Chem. 2009; 138: 7684

29. Thorat S, Kulkarni M, Thorat G. Controlled synthesis of nanosized polyaniline via unstirred, liquid-liquid interfacial polymerization process. Chem Chem Technol. 2015; 9( 2): 143-148.

30. Al-Daghman ANJ, Ibrahim K, Ahmed NM, Abdullah Al-Messiere M. Effect of doping by stronger ions salt on the microstructure of conductive polyaniline-ES: structure and properties.JOBM. 2016; 8(4):175-183.

31. Sangamesha MA, Pushpalatha K, Shekar GA. Synthesis and characterization of conducting polyaniline/copper selenide nanocomposites. I J A C S. 2014; 2(3): 223-7.

32. Hosseini, S H, Oskooei S H A, Entezani A A. Toxic Gas and Vapour Detection by Polyaniline Gas Sensor. Iran Polym J, 2005; 14(4): 333-344.

33. Rozemarie1 M L, Andrei B, Liliana H, Cramariuc R, Cramariuc O. Electrospun Based Polyaniline Sensors - A Review. Mater Sci Eng. 2017; 209, 012063.

34. Winck A L, Santos J V C, Lenz D M, Tedesco D M. Development and characterization of gas sensors using thin films of polyaniline as active layer, Revista Matéria. 2018;23(4): 


$$
\begin{aligned}
& \text { التصنيع الكيميائي وخصائص البولي أنيلين الموصل } \\
& \text { سالي عادل عبدالهادي } \\
& \text { صلاح عبدالله حسون } \\
& \text { قسم الفيزياء، كلية العلوم للبنات، جامعه بغداد، بغداد ، العراق. }
\end{aligned}
$$

تم تصنيع مسحوق البولي أنيلين كيميائيا عن طريق الأكسدة المباثرة للأنيلين. حيث نم توصيف البوليمر الناتج من خلال نتائج القياسات

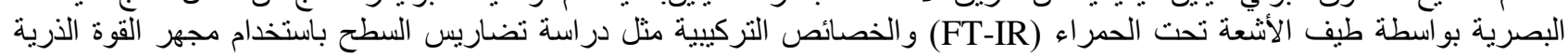
(AFM) الكلمات المفتاحية: مجهر القوة الذرية، التصنيع الكيميائي، البولي أنيلين الموصل، المجهر الاكتروني الماسح. 